\title{
Non-reloading coal transportation in the eastern inclined shaft of "Raspadskaya" mine
}

\author{
Vadim Yurchenko ${ }^{1,{ }^{*}}$ and Valeriy Nesterov ${ }^{1}$ \\ ${ }^{1}$ T.F. Gorbachev Kuzbass State Technical University, 28, Vesennyaya, Kemerovo, 650000
}

\begin{abstract}
The planned increase in the mine output from 6.5 to 13.6 million tons per year has set the task of reconstructing a conveyor transport in the eastern inclined shaft of the Raspadskaya mine. The roadway length is $4100 \mathrm{~m}$; the reduced inclination angle is $+7^{\circ} 40^{\prime}$. An attempt was made to combine all the positive global practices in one project: the distribution of drive power along the length of a conveyor belt, minimizing the capital cost of implementation. Within the framework of this article, an approach to choosing the speed of a conveyor belt is discussed, a comparative analysis of the two most common types of intermediate "tripper-type" and "belt-to-belt" drives is given; calculation of a belt conveyor with intermediate "belt-to-belt" drives providing non-reloading conveying in the eastern inclined shaft. Pull force calculations showed that a conveyor belt with four intermediate "belt-to-belt" drives can be implemented as follows: belt width $1400 \mathrm{~mm}$, belt speed $-4.0 \mathrm{~m} / \mathrm{s}$, mono-material load-carrying belt PVG-4000, mono-material drive belt - PVG-1400, 2-pulley drive units when mounted on one side: head drive power $-2 \times 1000=2000$ $\mathrm{kW}$, intermediate drive power $-2 \times 1600=3200 \mathrm{~kW}$. Thus, the use of a conveyor belt with four intermediate "belt-to-belt" drives in the inclined shaft will give the following results: non-reloading transportation over the entire length of the shaft, reducing the additional degradation of transported coal due to the exclusion of reloading points, minimizing costs through the use of less durable belts, minimizing costs of sinking an inclined shaft of a smaller cross-section.
\end{abstract}

\section{Introduction}

The task arose due to the planned increase in the mine output from 6.5 to 13.6 million tons per year. The length of the reconstructed eastern inclined shaft will be $4100 \mathrm{~m}$; the reduced inclination angle is $+7^{\circ} 40^{\prime}$.

The increase in the mine performance is associated with an increase in the daily output to 38,000 tons, which in turn requires the re-equipment of conveyor transport in the inclined shaft.

${ }^{*}$ Corresponding author: yvm@kuzstu.ru 


\section{Results and discussion}

The largest average load flow per minute [1] occurs when the time spent directly on coal mining is no more than 18 hours in 4 shifts, and the feed rate of load to be conveyed is not lower than 0.75

$$
a_{1(n) 1}=\frac{A_{c M}}{60 \cdot T_{c M} \cdot k_{n}}=12666,6 / 60 \times 6 \times 0,75=46,9 \mathrm{t} / \mathrm{min} .
$$

Knowing the average load flow per minute allows determining the operating conveyor load

$$
Q_{\ni}=60 a_{1(n) 1} k_{t}, \mathrm{t} / \mathrm{h}
$$

where $k_{t}$ is the feed rate, depending on the full length $L$ conveyor loading time $t_{\kappa}=$ $L / 60 \times V_{\lambda}$ and the feed rate variation factor $k_{1}$.

When choosing the optimal conveyors for transporting material over long distances, the determining factors are reliability, capital and operating costs, which are determined by such technical characteristics as belt width, strength and speed $[2,3]$.

Comparison of the operating conveyor load with the peak conveyor performance, which is determined by the conveyor capacity, allows making the choice of parameters such as the belt width and speed (Table 1).

\begin{tabular}{|c|c|c|c|c|}
\hline $\begin{array}{ll}\text { Parameters } & \text { Speed, } \mathrm{m} / \mathrm{s} \\
\end{array}$ & 3.15 & 4.0 & 4.5 & 5.0 \\
\hline Conveyor loading time $t_{\kappa}$, min & 21,7 & 17,1 & 15,2 & 13.6 \\
\hline$k_{t}$ at $k_{1}=\mathbf{1 , 2}$ & 1,06 & 1,075 & 1,085 & 1,095 \\
\hline$Q_{3}, \mathbf{t} / \mathbf{h}-$ operating conveyor load & 2982 & 3025 & 3053 & 3081 \\
\hline \multicolumn{5}{|c|}{ Belt length $1200 \mathrm{~mm}, \beta_{1}=35^{\circ}, \mathrm{S}=0,175 \mathrm{~m}^{2}$} \\
\hline Conveyor capacity $Q_{\kappa n p}, \mathbf{t} / \mathbf{m i n}$ & 29,7 & 37,8 & 42,5 & 47,3 \\
\hline Peak conveyor performance, $t / h$ & 1782 & 2268 & 2550 & 2838 \\
\hline \multicolumn{5}{|c|}{ Belt length $1400 \mathrm{~mm}, \beta_{1}=35^{\circ}, S=0,237 \mathrm{~m}^{2}$} \\
\hline Conveyor capacity $Q_{\kappa n p}$, t/min & 40,3 & 51,2 & 57,6 & 64,0 \\
\hline Peak conveyor performance, $t / h$ & 2418 & 3072 & 3456 & 3840 \\
\hline \multicolumn{5}{|c|}{ Belt length $1600 \mathrm{~mm}, \beta_{1}=35^{\circ}, \mathrm{S}=0,312 \mathrm{~m}^{2}$} \\
\hline Conveyor capacity $Q_{\kappa_{n p}}$, t/min & 53,0 & 67,4 & 75,8 & 84,2 \\
\hline Peak conveyor performance, $t / h$ & 3180 & 4044 & 4548 & 5052 \\
\hline
\end{tabular}

Table 1. Comparative data on the conveyor capacity at various belt speeds $[4,5]$

It is quite understandable that existing conveyors with a belt width of $1200 \mathrm{~mm}$ and a speed of $3.15 \mathrm{~m} / \mathrm{s}$ will not provide the required performance under conditions of the new shift schedule. During the reconstruction of transport, it is tempting to minimize costs: without increasing the belt width and without increasing the cross-section of the mine, increase the conveyor performance by increasing the speed to $6.3 \mathrm{~m} / \mathrm{s}$. But the use of high speeds taking into account a service life of inland rollers of 10,000 hours [4] will drastically reduce the reliability of the conveyor belt. The use of new hot-formed rollers with a service life of 50,000 hours [5] manufactured by Promtyazhmash JSC in Taganrog will help to resolve this problem. 
Thus, taking into account all the facts considered (Table 1), it is proposed to adopt the following parameters of the conveyor belt: belt width $-1400 \mathrm{~mm}$, belt speed $-4.0 \mathrm{~m} / \mathrm{s}$.

The second issue that needs to be discussed is conveyor length and drive power consumption. One of the main priorities of a long belt conveyor is non-reloading transportation, which excludes the additional coal degradation and belt wear. The calculation of conveyor pull for the entire length of the inclined shaft showed that the total drive power is $10520 \mathrm{~kW}$. Modern inland manufacturers do not produce drive units of the required power. In addition, the most durable steel-reinforced rubber belts do not provide the necessary factor of safety.

When designing long belt conveyors, the principle of distributing drive power along the length of the flight is increasingly used in world practice [6, 7]. The implementation of this principle is carried out by the use of intermediate drives - boosters. Among others, "trippertype" and "belt-to-belt" boosters found the greatest application.

The first design has three significant drawbacks. They consist in the fact that additional reloading points appear, leading to the additional degradation of transported coal and belt wear. In addition, a reloading point requires an increase in the height of the shaft, which will lead to an increase in its cross section and to an increase in the cost of its sinking.

The second design is devoid of these drawbacks, but requires a highly professional attitude to the selection and configuration of drive control equipment, which ensures the sequential start-up of intermediate drives and prevents the drive belt slippage relative to the load-carrying one. It should be noted that the widespread use of frequency control of asynchronous electric motors completely solves this problem.

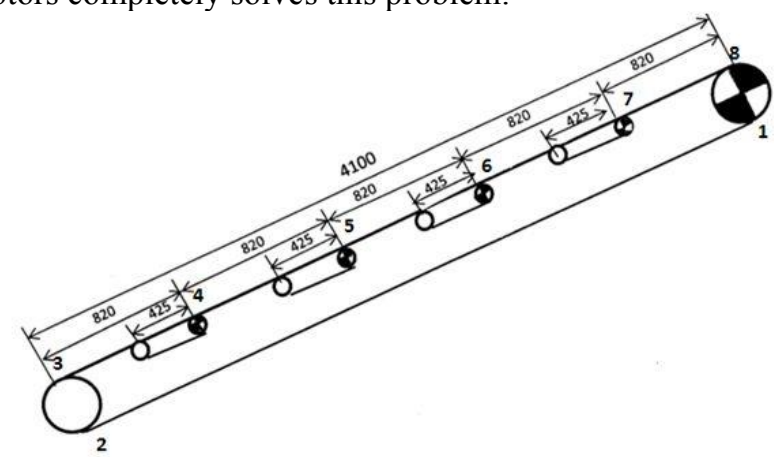

Fig. 1. Design scheme of a conveyor belt with four intermediate "belt-to-belt" drives

As a retrospective review shows, the experience of operating an intermediate "belt-tobelt" drive is known both abroad [8] and in Russia [9, 10, 11].

Thus, in order to ensure non-reloading transportation in the eastern inclined shaft, a belt conveyor with intermediate "belt-to-belt" drives is recommended (Fig. 1).

A closed loop drive belt driven by two independent pulleys is adopted as an intermediate "belt-to-belt" drive (Fig. 2). 


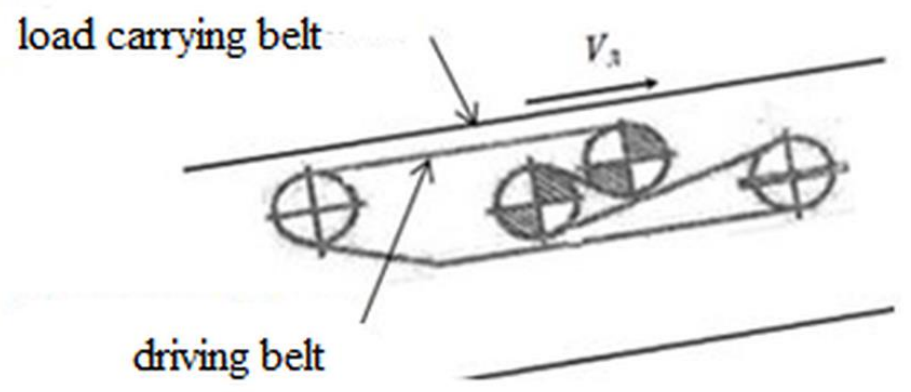

Fig. 2. The diagram of the intermediate "belt-to-belt" drive with two independent pulleys

The number of intermediate drives is determined by the strength of the load-carrying belt [12]

$$
n>\frac{k_{n} \times n_{n \times} \times W_{\Sigma}}{S_{p a s}}\left(1+\frac{\xi}{e^{\mu \bullet \alpha}-1}\right)
$$

where $k_{H}=1.15$ is coefficient of uneven distribution of tension on the intermediate drives with $n<4 ; n_{n p}=8$ is belt safety factor; $W_{\Sigma}$ is total resistance to the movement of the load-carrying belt along the entire length of the conveyor path, даH; $S_{p a з}$ is tensile load of the load-carrying belt, дан; $\xi=1.1$ is coefficient of additional resistance of the drive belt; $e^{\mu \bullet \alpha}$ is pull factor.

For these conditions, the number of intermediate drives is assumed to be four. When using less durable load-carrying mono-material PVG-4000 belt, the total drive power will be $10000 \mathrm{~kW}$. It is advisable to divide the entire length of the conveyor into five sections of 820 meters (Fig. 1) so that each section has power of $2000 \mathrm{~kW}$.

The pulling force generated by a drive with power $2000 \mathrm{~kW}$ is determined by the formula

$$
F_{n}^{N}=\frac{102 \times N_{n} \times \eta}{V_{n} \times k}, \text { даН }
$$

where $V_{\pi}=4.0 \mathrm{~m} / \mathrm{s}$ is belt speed, $k=1.32$ is safety factor, $\eta=0.85$ is drive efficiency.

The possible pulling force $F_{n 2}^{B}$ transmitted to the load-carrying belt by friction from the drive belt [13] is determined as follows

$$
F_{n 2}^{B}=\mu \times L_{n}\left(q_{\pi}^{o}+q_{2}\right) \times \cos \beta, \text { даН, }
$$

where $\mu=0.3$ is coefficient of adhesion between drive and load-bearing belts,

$q_{\Omega}^{o}=50.4 \mathrm{~kg} / \mathrm{m}$ is load-carrying belt mass per unit length,

$q_{2}=210 \mathrm{~kg} / \mathrm{m}$ is load mass per unit length with conveyor capacity of $3024 \mathrm{t} / \mathrm{h}$,

$\beta=7^{\circ} 40^{\prime}$ is weighted inclined shaft angle. 
Based on the equality $F_{n}^{N}=F_{n 2}^{6}$, the length of the intermediate drive is determined as follows

$$
L_{n}=\frac{102 \times N_{n} \times \eta}{V_{\pi} \times k \times \mu \times\left(q_{\pi}^{o}+q_{2}\right) \times \cos \beta}, \mathrm{M} .
$$

For the adopted conditions, the length of the intermediate drive was $425 \mathrm{~m}$. The power of the intermediate drive $N_{n n}$ to overcome the forces of resistance to movement of the drive belt (Fig. 2) will be $1200 \mathrm{~kW}$. Then the total power of the intermediate drive $N_{n}^{\Sigma}=N_{n}+N_{n \pi}$ is $3200 \mathrm{~kW}$. In order to reduce the space for placing an intermediate drive with two pulleys, drive units with power $N_{n}^{\Sigma}=2 \times 1600 \mathrm{~kW}$ should be placed on the conveyor's running side.

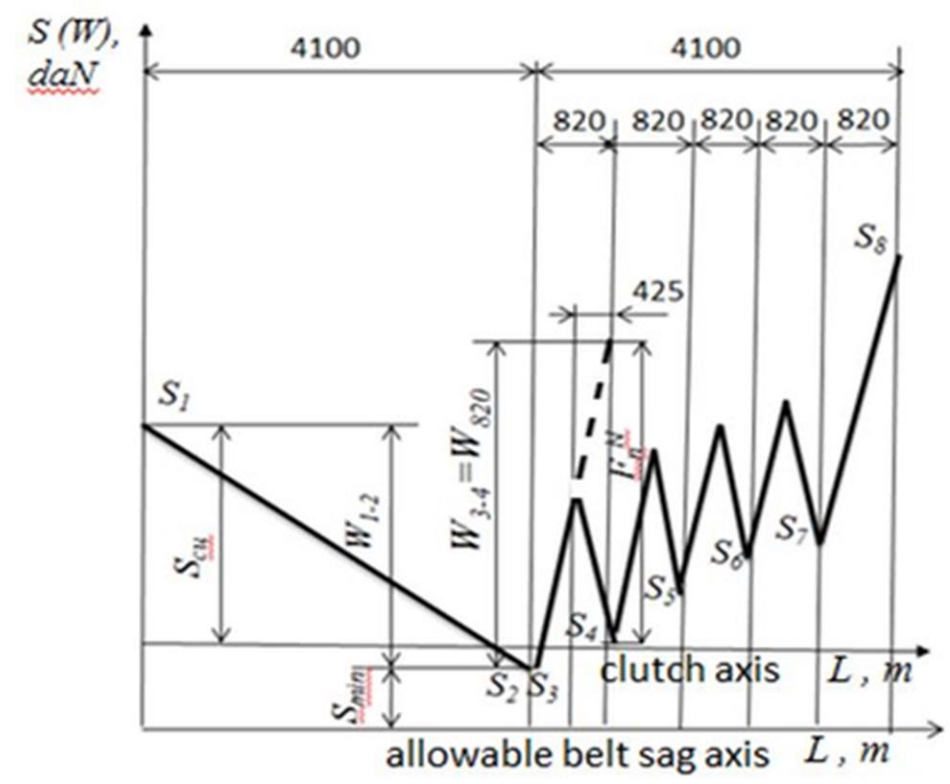

Fig. 3. The tension diagram of the conveyor belt with four intermedimate "belt-to-belt" drives

In addition, the drive units must be equipped with Flender bevel-helical gearboxes, which will allow them to be placed along the conveyor to reduce the required shaft width.

As can be seen in Fig. 3, without an intermediate drive, the tension of the load-carrying belt in $820 \mathrm{~m}$ long section 3-4 would increase by the value of resistance to movement $W_{3-4}=W_{820}$. But the presence of an intermediate "belt-to-belt" drive with a length of $425 \mathrm{~m}$ helps to reduce the tension of the load-carrying belt in the section 3-4 by the amount of pull $F_{n}^{N}=F_{n 2}^{6}$ developed by it.

The dispersion of power of the intermediate drives along the length of the conveyor results in significant decrease in the maximum load-carrying belt tension (Fig. 3), which will allow the use of less durable belts, while ensuring the necessary factor of safety.

Pull calculations showed that a conveyor belt with four intermediate "belt-to-belt" drives can be designed as follows:

belt width $-1400 \mathrm{~mm}$,

belt speed $-4.0 \mathrm{~m} / \mathrm{s}$, 
mono-material the load-carrying belt - PVG-4000, mono-material drive belt - PVG-1400, 2-pulley drive units when mounted on one side: head drive power $-2 \times 1000=2000 \mathrm{~kW}$, intermediate drive power $-2 \times 1600=3200 \mathrm{~kW}$.

\section{Conclusion}

The use of a conveyor belt with four intermediate "belt-to-belt" drives to ensure coal transportation in the eastern inclined shaft will allow:

- load conveying without reloading, excluding the additional degradation of transported coal and belt wear,

- minimizing costs of sinking an inclined shaft of a smaller cross-section,

- minimizing costs through the use of less durable load-carrying and drive belts.

\section{References}

1. Basics of designing underground transport of new and operating coal mines (Skochinsky Mining Institute, Moscow, 1986)

2. S. Zamorano, Bulk Solids Handling, 30, 416 (2010)

3. M.A. Alspaugh. Measurement. 143, 246 (2019)

4. State Standard GOST R 57841-2017. Mining Equipment. Mine Belt Conveyors. Rollers. General Specifications (Standardinform, Moscow, 2017)

5. Promtyazhmash JSC Bureau, The installation of hot-formed conveyor rollers reduces the technical costs of the enterprise (Accessed 20 December 2019)

6. M.S. Masaki, Lijun Zhang, Xiaohua Xia, Chinese Control Conference (CCC), 36, 526 (2017)

7. M.S. Masaki, Lijun Zhang, Xiaohua Xia, Journal of Cleaner Production, 201, 1768 (2018)

8. T. Maron, C. Rausch, Mining Report, 150, 85 (2014)

9. V. Koloyarov, V. Gridchin, Coal, 9 (1992)

10. V. Koloyarov, V. Kutsankin, Mining informational and analytical bulletin (scientific and technical journal), 12, 38 (2009)

11. M. Kotov, O. Zaretsky, A. Sysoev, Y. Kurnikov, V. Yurchenko, Belt conveyor (USSR Academy of Sciences, Moscow, 1990)

12. R. Volkov, A.Gnutov, V. Diyachkov, et al, Conveyors (Mechanical Engineering, Leningrad, 1984)

13. Yu. Tarasov, D. Yungmeister, V. Avdeev, Belt conveyor boosters (Nedra, Moscow, 1996) 